\title{
External hydrocephalus in primary hypomagnesaemia: a new finding
}

Bappal Bhasker, Palany Raghupathy, T M Rajendran Nair, Syed Riaz Ahmed, Vasantha deSilva, Bipul Chandra Bhuyan, Saleh Mohammad Al Khusaiby

\begin{abstract}
This paper reports a new finding in two siblings with primary hypomagnesaemia as a result of renal magnesium wasting, namely, rapidly increasing head size. External hydrocephalus and brain shrinkage in primary hypomagnesaemia seen on computed tomography of the brain with reversibility after magnesium treatment has not been reported previously. (Arch Dis Child 1999;81:505-507)
\end{abstract}

Keywords: primary hypomagnesaemia; external hydrocephalus

The metabolic abnormalities in primary hypomagnesaemia and the resulting clinical manifestations are well documented. We describe for the first time the association of external hydrocephalus in two siblings with primary hypomagnesaemia, as a result of isolated renal magnesium wasting.

External hydrocephalus is defined as a rapid

Paediatric

Endocrinology and

Metabolism,

Department of Child

Health, Royal

Hospital, PO Box 1331,

CPO SEEB, Postcode

111, Muscat, Sultanate

of Oman

B Bhasker

P Raghupathy

T M R Nair

Paediatric Neurology, Department of Child Health, Royal Hospital S R Ahmed

Department of Clinical Pathology, Royal Hospital

V deSilva

Department of Radiology, Royal Hospital

B C Bhuyan

Neonatology,

Department of Child

Health, Royal Hospital

S M Al Khusaiby

Correspondence to:

Professor P Raghupathy,

Department of Child Health,

Christian Medical College

and Hospital, Vellore,

PIN 632 004, India

email:raghu@

cmcvellore.ac.in

Accepted 28 July 1999 increase in head circumference, with computed tomography (CT) evidence of an increased collection of cerebrospinal fluid in the subarachnoid space, predominantly bifrontal, together with a normal or minimally dilated ventricular system..$^{1-3}$

\section{Case reports}

PATIENT 1

Patient 1 was the third child of consanguineous parents (first cousins), born at term. At birth, her weight was $3200 \mathrm{~g}$, head circumference $34 \mathrm{~cm}$, and body length $50 \mathrm{~cm}$.

She was breast fed and growing normally. When 4 months old, she was referred with uncontrolled myoclonic seizures despite three weeks of oral clonazepam and parenteral corticotrophin.

She was lethargic and unable to suck or swallow well. She did not fix or follow objects. Her head appeared large $(46.5 \mathrm{~cm} ; 97$ th centile) (fig 1A), her weight was $7500 \mathrm{~g}$ (50th centile), length $64.2 \mathrm{~cm}$ (50th centile), and body mass index (BMI) $18.2 \mathrm{~kg} / \mathrm{m}^{2}$ (> 50th centile). The anterior fontanelle was open, full, and not bulging. Her developmental age, assessed by the Denver developmental scoring system, was approximately 8 weeks. Neurological examination revealed generalised hypotonia, decreased power, diminished deep tendon reflexes, and positive Chvostek sign. She had intermittent rotatory nystagmus and normal ocular fundi.

Her serum calcium concentration was low (1.6 mmol/litre) (normal value, 1.7-2.3).
Other biochemical screening investigations were normal. An electroencephalogram (EEG) revealed generalised polymyoclonic epileptic discharges.

Because seizures were refractory to intravenous calcium treatment, serum magnesium was estimated and found to be $0.18 \mathrm{mmol} /$ litre (normal value, 0.65-1.25). Convulsions stopped promptly with $1.5 \mathrm{ml}$ of $50 \%$ magnesium sulphate solution $(2 \mathrm{mmol} / \mathrm{ml}$ of magnesium) twice daily (intramuscularly). Rotatory nystagmus improved by the sixth day. The serum magnesium concentration rose to $0.91 \mathrm{mmol} /$ litre within five days and normocalcaemia was achieved spontaneously, without additional calcium. Stopping the administration of magnesium caused serum magnesium and calcium values to fall within three days (to $0.35 \mathrm{mmol} /$ litre for magnesium). Hence, we considered the diagnosis of primary hypomagnesaemia.

After recommencing magnesium treatment, her general activity, muscle tone, and power
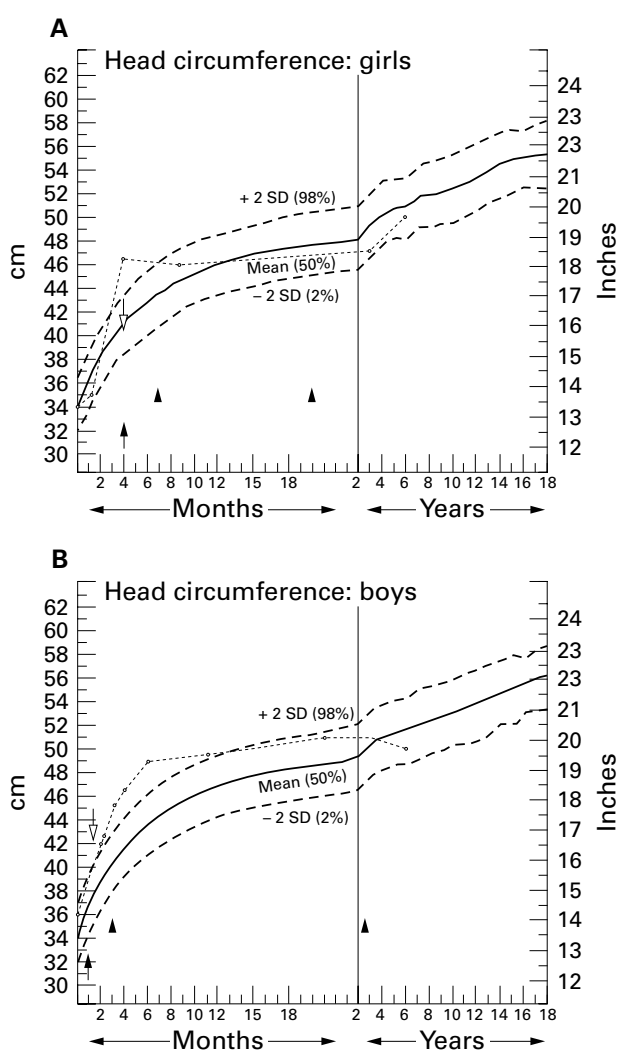

Figure 1 Head circumference charts. (A) The thin broken line represents patient $1 ;(B)$ the thin broken line represents patient 2. Closed arrow, presentation/diagnosis; open arrow, treatment commenced; closed arrowhead, computed tomography scan brain done. 

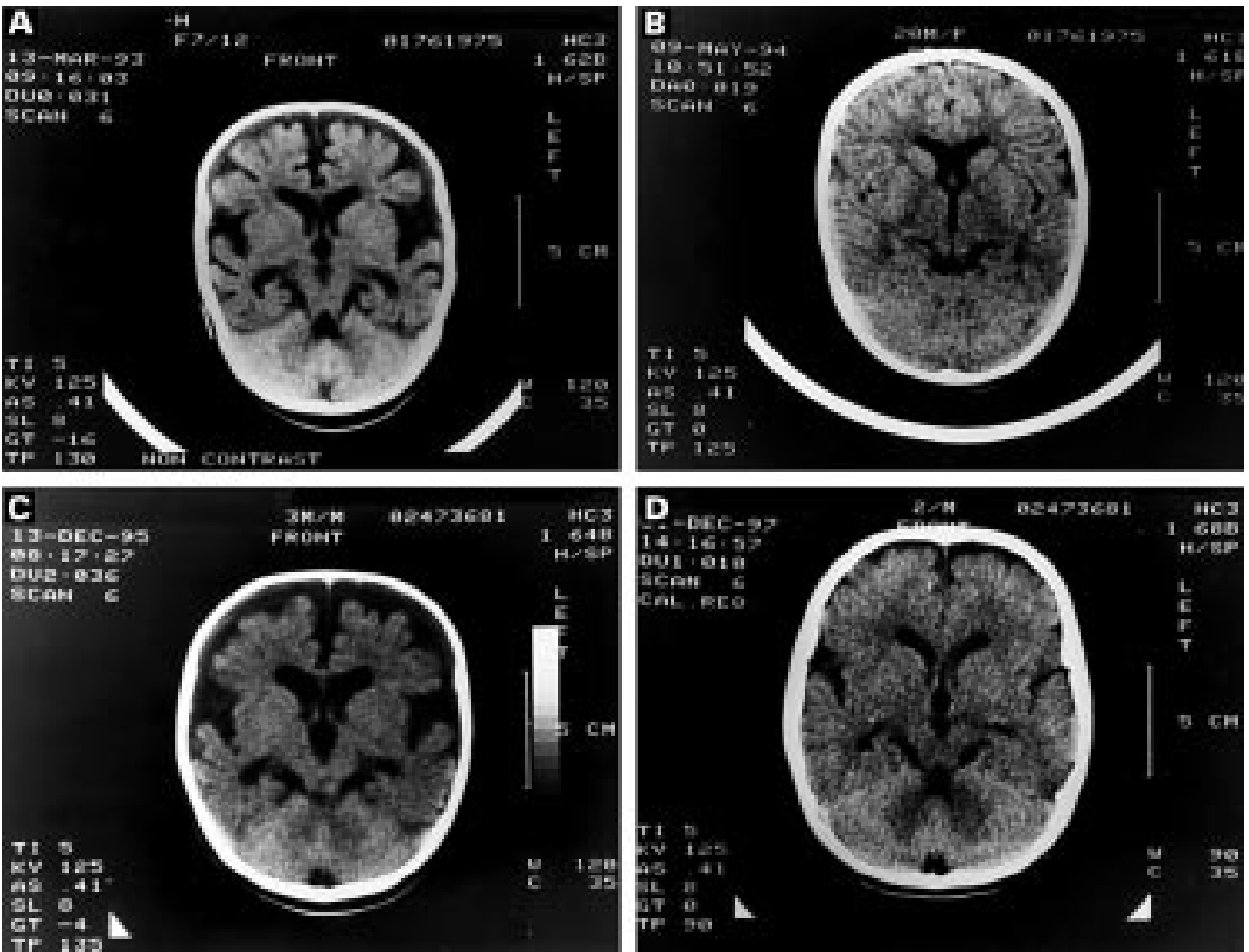

Figure 2 Computed tomography brain scans of the two siblings. (A) Patient 1, external hydrocephalus and cerebral atrophy noted in the early stage of the disease. (B) Patient 1, normal appearance after 13 months of magnesium treatment. (C) Patient 2, similar early changes as seen in the elder sibling. (D) Patient 2, normal appearance after treatment with magnesium for 24 months.

improved rapidly and she gradually resumed breast feeding. After six weeks, parenteral magnesium was discontinued and $150 \mathrm{mg}$ (12 mmol magnesium) of oral magnesium amino acid chelate (Lamberts Health Care, Kent, UK) was given three times daily. Serum magnesium stabilised at $0.5-0.6 \mathrm{mmol} / \mathrm{litre}$. Neurological and developmental recovery occurred in the first three months. A CT brain scan at 7 months of age suggested global cerebral atrophy, more pronounced in the frontoparietal area, generalised subarachnoid widening, and a mildly enlarged ventricular system (fig 2A). The anterior fontanelle closed by 18 months of age. The disappearance of external hydrocephalus and brain shrinkage was noted on CT brain scan (fig 2B) at 20 months of age.

At 6 years of age, her head circumference was $50 \mathrm{~cm}$ (<50th centile), and growth and development were normal. Her social age was assessed by the Denver developmental scoring system to be 5 years and 2 months and her IQ as 86. EEG was normal. She had normal fractional excretion of sodium, potassium, chloride, calcium, and phosphate with no proteinuria, glycosuria, or aminoaciduria.

Table 1 Magnesium studies in patient 1

\begin{tabular}{lccc}
\hline & Day 0 & Day 3 & Day 5 \\
\hline Urine volume (litres) & 0.764 & 0.815 & 0.630 \\
Serum magnesium $(\mathrm{mmol} / \mathrm{l})$ & 0.37 & 0.59 & 0.63 \\
Serum creatinine $(\mu \mathrm{mol} / \mathrm{l})$ & 37 & 34 & 36 \\
Urinary magnesium $(\mathrm{mmol} / \mathrm{l})$ & 0.04 & 6.5 & 4.02 \\
Urinary creatinine $(\mu \mathrm{mol} / \mathrm{l})$ & 3.33 & 4.6 & 3.86 \\
Tubular reabsorption of magnesium $(\%)$ & 99.85 & 91.86 & 90.56 \\
Fractional excretion of magnesium $(\%)$ & 0.15 & 7.14 & 9.44 \\
\hline
\end{tabular}

Magnesium was studied after discontinuing treatment for two weeks. A basal blood sample and 24 hour urine sample were collected on day 0 . Intramuscular $3 \mathrm{ml}$ injections of $50 \%$ magnesium sulphate $(6 \mathrm{mmol} ; 0.375 \mathrm{mmol} /$ $\mathrm{kg}$ ) were given daily from days 1 to 5 . The renal tubular maximum for magnesium, the fractional excretion, and the percentage of tubular reabsorption of magnesium were estimated (table 1).

PATIENT 2

Patient 2 (sibling of patient 1) was born normally at term -weight $3800 \mathrm{~g}$, body length $50 \mathrm{~cm}$, head circumference $36 \mathrm{~cm}$ at birth. Although asymptomatic, in view of his sibling's history, he was investigated at 4 weeks of age. His serum magnesium was $0.17 \mathrm{mmol} /$ litre, serum calcium $2.19 \mathrm{mmol} /$ litre, and parathyroid hormone $9.7 \mathrm{pmol} /$ litre (normal, 1.26-7.58). However, his parents were sceptical when informed of the results and declined treatment. He was admitted at 6 weeks with jitteriness and increasing head size (fig 1B). Clinically, he was well nourished, weighing $7500 \mathrm{~g}$ ( $>97$ th centile), with a body length of $61 \mathrm{~cm}$ (>50th centile), head circumference of $39.5 \mathrm{~cm}$ ( $>97$ th centile), and BMI of $20 \mathrm{~kg} / \mathrm{m}^{2}$. He was alert, visually attentive, without nystagmus or signs of increased intracranial tension. Jitteriness and hyper-reflexia were observed. EEG revealed generalised dysrhythmia. He received parenteral magnesium initially and, subsequently, $150 \mathrm{mg}$ oral magnesium chelated salt thrice daily. A CT brain scan at 3 months showed widening of the subarachnoid space in the bifrontal, biparietal, 
and interhemispheric area, with minimally dilated ventricles (fig $2 \mathrm{C}$ ).

At 15 months, anterior fontanelle closure was noted. At 3 years, we performed the Beery developmental test of visual motor integration and the Goodenough-Harris drawing test. The patient's IQ was assessed as 90 and his social age as 2 years 8 months. Renal tubular function was not studied because 24 hour urine collection was difficult without catheterisation. EEG was normal. A CT brain scan, repeated at 27 months, showed complete disappearance of external hydrocephalus and remarkable improvement of brain shrinkage (fig 2D).

\section{Discussion}

Rapidly increasing head size, signifying the early adverse effect of hypomagnesaemia on the growing brain, was observed in both siblings without increased intracranial pressure. There was no vomiting; the anterior fontanelle was full, and not bulging. Delayed diagnosis in sibling 1 facilitated earlier detection of primary hypomagnesaemia in the younger sibling, two weeks before the head began to enlarge. In the elder sibling, even though her head was large at presentation, this finding was overshadowed by the neurological symptoms of hypomagnesaemia.

It is noteworthy that magnesium was conserved maximally $(99.85 \%)$ during the hypo- magnesaemic state on day 0 , but when serum magnesium concentrations became normal, magnesium excretion was high, suggesting a lowered threshold. Fractional excretion of magnesium was $>5 \%$ with normal serum values, so the diagnostic criterion for primary hypomagnesaemia caused by renal tubular magnesium wasting is fulfilled. ${ }^{4}$

Known causes of cerebral atrophy or brain shrinkage such as dehydration, protein energy malnutrition, hypoalbuminaemia, or electrolyte imbalance were absent at the time of CT scan. The precise mechanism leading to reversible external hydrocephalus in this condition remains to be explored. Derangement of one or more enzymatic function in magnesium deficiency might be responsible for brain shrinkage. Improvement with magnesium treatment is remarkable, so early diagnosis and aggressive and prolonged treatment are imperative.

1 Alvarez LA, Maytal J, Shinnar S. Idiopathic external hydrocephalus: natural history and relationship to benign familial macrocephaly. Pediatrics 1986;77:901-7.

2 Maytal J, Alvarez LA, Elkin CM, Shinnar S. External hydrocephalus: radiologic spectrum and differentiation of cerebral atrophy. Am $\mathcal{F}$ Roentgenol 1987;148:1223-30.

3 Koul R, Cherian E, Chacko A, Joshi R, Aithala G, Sankhla D. External hydrocephalus - a report of 16 cases from Oman. F Trop Pediatr 1998;44:153-6. 4 Sutton RAL, Domrongkitchaiporn S. Abnormal renal mag-
nesium handling. Miner Electrolyte Metab 1993;29:345-8. 